\title{
(6) OPEN ACCESS \\ Efficacy and safety of intravitreal aflibercept injection in wet age-related macular degeneration: outcomes in the Japanese subgroup of the VIEW 2 study
}

\author{
Yuichiro Ogura, ${ }^{1}$ Hiroko Terasaki, ${ }^{2}$ Fumi Gomi, ${ }^{3}$ Mitsuko Yuzawa, ${ }^{4}$ Tomohiro lida, ${ }^{5}$ \\ Miki Honda, ${ }^{6}$ Koichi Nishijo, ${ }^{7}$ Olaf Sowade, ${ }^{8}$ Tetsushi Komori, ${ }^{7}$ \\ Ursula Schmidt-Erfurth, ${ }^{9}$ Christian Simader, ${ }^{10}$ Victor Chong, ${ }^{11}$ for the VIEW 2 \\ Investigators
}

For numbered affiliations see end of article.

\section{Correspondence to}

Dr Yuichiro Ogura, Department of Ophthalmology and Visual

Science, Nagoya City University Graduate School of Medical

Sciences, 1 Kawasumi,

Mizuho-Cho, Mizuho-Ku,

Nagoya-shi, Aichi-ken

467-8602, Japan;

vitreous.surgeon@gmail.com

Received 12 February 2014

Revised 19 June 2014

Accepted 14 July 2014

Published Online First

8 August 2014

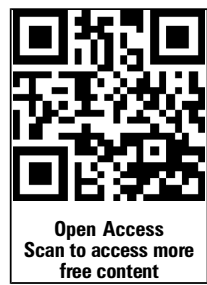

CrossMark

To cite: Ogura $Y$,

Terasaki H, Gomi F, et al.

$\mathrm{Br}$ I Ophthalmol

2015:99:92-97.

\section{ABSTRACT}

Background/aims To evaluate efficacy and safety of intravitreal aflibercept (IVT-AFL) in Japanese patients with wet age-related macular degeneration (WAMD) from the VIEW 2 trial.

Methods In this double-masked study, patients were randomised to: $0.5 \mathrm{mg}$ IVT-AFL every 4 weeks $(0.5 q 4)$; 2 mg IVT-AFL every 4 weeks (2q4); 2 mg IVT-AFL every 8 weeks (2q8) after 3 monthly injections; or $0.5 \mathrm{mg}$ ranibizumab every 4 weeks (Rq4). Main efficacy outcomes included vision maintenance and bestcorrected visual acuity (BCVA) at week 52 .

Results At week 52, all Japanese patients in the IVTAFL groups ( $n=70)$ maintained vision, compared with $96 \%$ of Japanese patients $(n=23 / 24)$ treated with ranibizumab. Japanese patients in all treatment groups showed improvement in BCVA after treatment. The Rq4, $2 q 4$ and $2 q 8$ groups experienced similar gains in BCVA from baseline. The $0.5 q 4$ group had higher gains due to an unexpected drop in BCVA between screening and baseline. Central retinal thickness and mean area of choroidal neovascularisation decreased in all treatment groups with similar magnitude. Ocular treatment-

emergent adverse events were balanced across treatment groups.

Conclusions IVT-AFL was effective and well tolerated in Japanese patients. Outcomes in this population were consistent with those in the overall VIEW 2 population. Trial registration number NCT00637377.

\section{INTRODUCTION}

The prevalence of age-related macular degeneration (AMD), a leading cause of blindness in industrialised countries worldwide, ${ }^{1}$ is increasing in Japan. ${ }^{2}$ The Funagata study showed that age-standardised prevalence of late AMD (including wet AMD (wAMD) and geographic atrophy) in right eyes was $1.1 \%$ for men and $0.3 \%$ for women. ${ }^{3}$ The prevalence of late AMD was similar to that observed for men $(1.2 \%)$ in the Blue Mountain Eye Study, which comprised mainly white patients, but was lower than that observed for women $(2.1 \%)$. While the prevalence of late AMD is similar, the proportion of AMD patients with wAMD is substantially higher among Japanese patients than white patients (70\% vs $10-30 \%)^{4}$
Unique characteristics of the Japanese wAMD population include male preponderance, ${ }^{5}{ }^{6}$ low incidence of large drusen, ${ }^{5-7}$ higher incidence of unilateral involvement, ${ }^{5-8}$ high rate of polypoidal choroidal vasculopathy (PCV), ${ }^{5-11}$ and lower rate of retinal angiomatous proliferation ${ }^{5}$ in comparison to white patients. Detachment of the retinal pigment epithelium and major haemorrhage are common among Japanese wAMD patients, while drusen in the fellow eye are uncommon. ${ }^{2}$ Furthermore, certain differences in risk alleles have been described in Japanese patients compared with white patients for various types of AMD, including WAMD. ${ }^{12}{ }^{13}$ Hence, the overall condition of wAMD differs in many respects from the disease presentation in white patients.

Current AMD treatment includes antivascular endothelial growth factor (VEGF) agents. Studies have demonstrated the safety and efficacy of two such agents, ranibizumab and bevacizumab, in Japanese patients. ${ }^{9} 10$ 14-16 Intravitreal aflibercept (IVT-AFL) is the most recently approved anti-VEGF treatment. Its safety and efficacy in a global population were demonstrated in the VIEW 1 and VIEW 2 studies. ${ }^{1}$ Given the distinct features of AMD in Japanese patients, and the fact that VIEW 2 is the largest study of anti-VEGF treatment for AMD conducted to date in a Japanese population, a subgroup analysis to demonstrate the efficacy and safety of IVT-AFL in the Japanese subpopulation of the VIEW 2 study was conducted.

\section{METHODS}

VIEW 2 (NCT00637377) was a prospective, double-masked, multinational, active-controlled, randomised, clinical trial. Eligible patients had subfoveal choroidal neovascularisation (CNV) or juxtafoveal CNV with subfoveal leakage demonstrated on fluorescein angiography (FA) with appropriate lesion characteristics. Since PCV is considered to be part of the AMD spectrum, patients with PCV lesions were not excluded.

Methods for the VIEW 2 study have been described elsewhere. ${ }^{1}$ Patients were randomised at 172 sites in Europe, the Middle East, Asia-Pacific, and Latin America in a 1:1:1:1 ratio to the following regimens: $0.5 \mathrm{mg}$ IVT-AFL every 4 weeks $(0.5 \mathrm{q} 4)$; $2 \mathrm{mg}$ IVT-AFL every 4 weeks (2q4); 2 mg IVT-AFL 
every 8 weeks $(2 q 8)$ after three injections at weeks 0,4 and 8 (to maintain masking, sham injections were given at the interim 4-week visits after week 8 ); or $0.5 \mathrm{mg}$ ranibizumab every 4 weeks (Rq4). The primary endpoint analysis was non-inferiority of IVT-AFL to ranibizumab in the proportion of patients maintaining vision at week 52 (losing $<15$ Early Treatment of Diabetic Retinopathy Study (ETDRS) letters, in the perprotocol set (PPS)), described in the primary publication. ${ }^{1}$ A predetermined number of Japanese patients were enrolled to allow for statistical evaluation of consistency of results between the Japanese subpopulation and the full study population based on Pharmaceutical and Medical Devices Agency (PMDA) recommendations for conducting global clinical trials. $^{17}$

The full analysis set (FAS) of the Japanese subpopulation included all randomised patients treated at any Japanese site that received any study medication and had a baseline and $\geq 1$ postbaseline best-corrected visual acuity (BCVA) assessment. The PPS included all FAS patients who (1) received $\geq 9$ doses of study drug and attended $\geq 9$ scheduled visits during the first year, (2) had not missed two consecutive injections before administration of the ninth injection (per patient), and (3) did not have major protocol violations. Sham injections were counted as doses administered for the purpose of defining the PPS. The PPS included patients who discontinued the study because of treatment failure, without a major protocol deviation, at any time during the first 52 weeks.

\section{RESULTS}

\section{Patient disposition and demographics}

Of the 1240 patients randomised in VIEW 2, ${ }^{1} 101$ (8\%) were Japanese, ranging between $8.2 \%$ in the $2 \mathrm{q} 8$ group and $8.6 \%$ in the Rq4 group. Among Japanese patients, 94 (93\%) completed the first year, while $7(7 \%)$ discontinued early due to adverse events or other reasons (figure 1).

Patients were predominantly male (78.2\%); mean age was 72 years. Demographic characteristics were similar across treatment groups (table 1).

\section{Disease characteristics}

While lesion type and mean central retinal thickness (CRT) were similar among groups, there were differences in baseline visual acuity (VA) letter score (as determined by the ETDRS letter chart), mean area of CNV, and mean total lesion size (table 1). Japanese patients had a mean (SD) baseline VA ETDRS letter score of 54.4 (13.2) letters (range 14-79 letters). Baseline VA was highest in the $2 \mathrm{q} 4$ group (58.8 (11.2) letters) and lowest in the $0.5 \mathrm{q} 4$ group (48.3 (13.7) letters). The low baseline VA observed for the $0.5 \mathrm{q} 4$ group is partially attributable to four patients whose BCVA scores decreased by more than 10 letters from screening to baseline (range: -11 to -20 letters). Mean baseline area of $\mathrm{CNV}$ was highest in the $\mathrm{Rq} 4$ group $\left(8.06(7.49) \mathrm{mm}^{2}\right)$ and lowest in the $2 \mathrm{q} 4$ group $\left(5.07(4.45) \mathrm{mm}^{2}\right)$. Disease characteristics were nearly identical between the FAS and PPS (data not shown).

\section{Treatment and exposure summary}

The mean number of active injections was similar in the Rq4 (12.9), 2q4 (12.7), and $0.5 \mathrm{q} 4$ (12.7) groups, while the $2 \mathrm{q} 8$ group had a lower mean number of active injections (7.9).

\section{Efficacy results}

Primary endpoint

The primary endpoint was the proportion of patients who maintained vision (lost $<15$ ETDRS letters). At week 52, all 70 patients treated with IVT-AFL maintained vision; 23 of 24
(96\%) of patients in the Rq4 group maintained vision (data not shown). The upper limit of the 95\% CIs between all IVT-AFL groups and the Rq4 group was below 10\% in Japanese patients, consistent with results in the overall population. Sensitivity analyses performed for the primary endpoint in the PPS (using observed values and worst observation carried forward methods, and considering all dropouts and treatment failures to be non-responders) demonstrated the same results as those in the primary analysis of the PPS using last observation carried forward (data not shown).

\section{Change from baseline in BCVA}

Japanese patients showed improvement in BCVA after treatment in all groups (figure 2A). Similar to the overall VIEW 2 study population, ${ }^{1}$ initial gains in BCVA were seen at week 1 in all groups with subsequent maintenance of gains through week 52 . The Japanese $0.5 \mathrm{q} 4$ group experienced a marked mean (SD) increase from baseline of 6.0 (10.1) ETDRS letters at week 1, compared with all other groups. Improvements among the three other groups were comparable (Rq4, 1.8 (5.4); 2q4, 2.3 (6.0); $2 \mathrm{q} 8,1.9(5.5))$. At week 52, the three groups, excluding the $0.5 \mathrm{q} 4$ group, had similar gains in ETDRS letter score (approximately $8-10$ letters), while the $0.5 \mathrm{q} 4$ group had a gain of 15.9 (10.6) letters. Adjusted mean gains obtained by analysis of covariance (ANCOVA) model including baseline value as a covariate to account for a possible baseline imbalance were generally comparable to these unadjusted mean values. The difference in improvement occurred during the first interval following the first injection administered, with an increase of six letters in this group as compared to a mean of two letters in all other treatment arms. The subsequent increase in BCVA over time was identical in magnitude and time among all groups. When the absolute BCVA from screening was considered, it became apparent that a transient and substantial decline in mean VA between screening and baseline in the $0.5 \mathrm{q} 4$ group contributed to this observation (figure 2B).

Among Japanese patients, the number of patients in the $0.5 \mathrm{q} 4$ group with a baseline BCVA score of $<50$ letters was 14, proportionally 1.6-2.8 times higher than other treatment groups. Additionally, for those three patients whose BCVA scores decreased by more than 10 letters from screening to baseline, an average increase of 29.3 letters was observed between baseline and week 1. Among patients in the other groups, the average BCVA score gain at week 1 was 2.0. Mean ETDRS letter score was markedly improved after treatment in all groups. The mean letter scores at week 52 were similar for all groups (range: 64.2-67.3).

\section{Change from baseline in CRT}

CRT decreased in patients in all groups (figure 3). In this population of Japanese patients, CRT decreased through week 12 or week 16, and reductions in CRTwere maintained through week 52. The magnitude of the mean (SD) change at week 52 was similar among groups, ranging from $-131.4(145.2) \mu \mathrm{m}$ in the $\mathrm{Rq} 4$ group and $-178.2(100.7) \mu \mathrm{m}$ in the $2 \mathrm{q} 4$ group.

\section{Change from baseline in CNV area}

Mean CNV area decreased after 52 weeks in all groups (data not shown). Mean (SD) changes ranged from -2.85 (3.92) $\mathrm{mm}^{2}$ in the $2 \mathrm{q} 4$ group to $-4.27(5.67) \mathrm{mm}^{2}$ in the $2 \mathrm{q} 8$ group. Adjusted mean changes obtained by ANCOVA model including baseline value as a covariate to account for a possible baseline imbalance were generally comparable with these unadjusted mean values. 


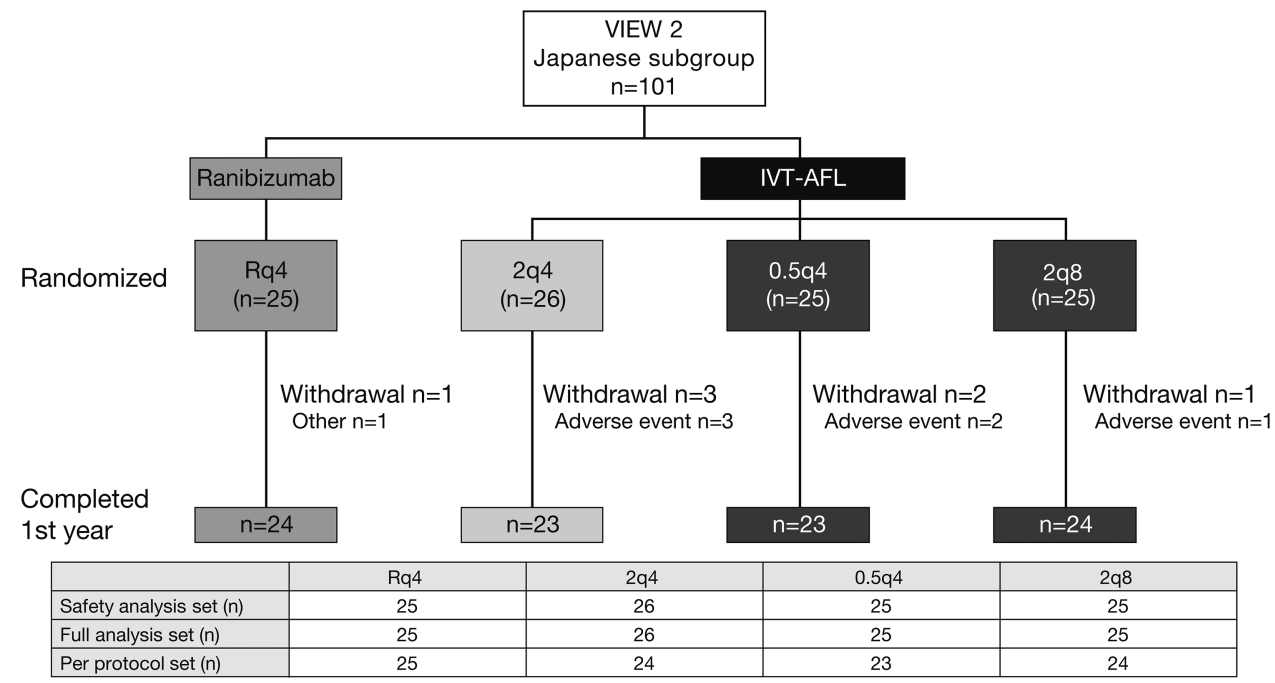

Figure 1 Patient disposition.

No significant changes were found in the IVT-AFL groups in comparison with ranibizumab (ANCOVA).

Proportion of patients without fluid at week 52

At week 52, the proportion of patients without retinal fluid, defined by the masked reading centre as an absence of cystic retinal oedema and subretinal fluid on optical coherence tomography, was greater in the IVT-AFL groups (69.6-82.6\%) than in the ranibizumab group (37.5\%).

\section{Safety}

The incidence of ocular treatment-emergent adverse events (TEAE) in the study eye was similar in all groups; however, the rate was slightly higher in patients treated with IVT-AFL $(60.5 \%)$ than in those treated with ranibizumab $(52.0 \%)$. This

Table 1 Patient demographics and disease characteristics

\begin{tabular}{|c|c|c|c|c|c|c|}
\hline & \multirow{2}{*}{$\begin{array}{l}\text { Ranibizumab } \\
\text { Rq4 } \\
\mathrm{n}=25\end{array}$} & \multicolumn{4}{|c|}{ Intravitreal aflibercept } & \multirow[b]{2}{*}{$\begin{array}{l}\text { Total } \\
n=101\end{array}$} \\
\hline & & $\begin{array}{l}2 q 4 \\
n=26\end{array}$ & $\begin{array}{l}0.5 q 4 \\
n=25\end{array}$ & $\begin{array}{l}2 q 8 \\
n=25\end{array}$ & $\begin{array}{l}\text { IVT-AFL } \\
\text { combined } n=76\end{array}$ & \\
\hline \multicolumn{7}{|l|}{ Sex } \\
\hline Male, n (\%) & $20(80.0)$ & $23(88.5)$ & $17(68.0)$ & $19(76.0)$ & $59(77.6)$ & 79 (78.2) \\
\hline Female, n (\%) & $5(20.0)$ & $3(11.5)$ & $8(32.0)$ & $6(24.0)$ & 17 (22.4) & $22(21.8)$ \\
\hline \multicolumn{7}{|l|}{ Age (years) } \\
\hline Mean (SD) & $72.0(6.6)$ & $70.1(8.0)$ & $73.7(10.1)$ & $70.6(7.8)$ & $71.4(8.7)$ & $71.6(8.2)$ \\
\hline Range & $60-86$ & $56-82$ & $58-89$ & $58-84$ & $56-89$ & $56-89$ \\
\hline $50-<65, \mathrm{n}(\%)$ & $3(12.0)$ & $7(26.9)$ & $6(24.0)$ & $5(20.0)$ & $18(23.7)$ & $21(20.8)$ \\
\hline $65-<75, \mathrm{n}(\%)$ & $14(56.0)$ & $9(34.6)$ & $6(24.0)$ & $13(52.0)$ & $28(36.8)$ & $42(41.6)$ \\
\hline$\geq 75, \mathrm{n}(\%)$ & $8(32.0)$ & $10(38.5)$ & $13(52.0)$ & $7(28.0)$ & $30(39.5)$ & 38 (37.6) \\
\hline \multicolumn{7}{|l|}{ BCVA (ETDRS letters) } \\
\hline Mean (SD) & $56.2(11.7)$ & $58.8(11.2)$ & $48.3(13.7)$ & $54.2(14.5)$ & $53.8(13.7)$ & $54.4(13.2)$ \\
\hline Range & $22-74$ & $34-79$ & $14-68$ & $20-74$ & $14-79$ & $14-79$ \\
\hline \multicolumn{7}{|l|}{ CRT $(\mu \mathrm{m})$} \\
\hline Mean (SD) & $321.2(113.8)$ & $327.6(97.0)$ & $354.6(159.6)$ & $345.4(185.9)$ & $342.4(149.9)$ & $337.1(141.6)$ \\
\hline Range & $175-580$ & $128-586$ & $142-761$ & $161-868$ & $128-868$ & $128-868$ \\
\hline \multicolumn{7}{|l|}{ CNV area $\left(\mathrm{mm}^{2}\right)$} \\
\hline Mean (SD) & $8.06(7.49)$ & $5.07(4.45)$ & $5.46(3.82)$ & $6.86(4.42)$ & $5.79(4.26)$ & $6.35(5.29)$ \\
\hline Range & $1.0-28.8$ & $0.1-16.3$ & $0.7-16.2$ & $0.5-15.4$ & $0.1-16.3$ & $0.1-28.8$ \\
\hline \multicolumn{7}{|l|}{ Total lesion size $\left(\mathrm{mm}^{2}\right)$} \\
\hline Mean (SD) & $8.73(8.19)$ & $5.47(4.98)$ & $6.09(4.23)$ & $7.54(4.79)$ & $6.35(4.70)$ & $6.94(5.81)$ \\
\hline Range & $1.1-28.8$ & $0.1-20.8$ & $1.3-16.2$ & $0.5-15.9$ & $0.1-20.8$ & $0.1-28.8$ \\
\hline \multicolumn{7}{|l|}{ Lesion type } \\
\hline Occult, n (\%) & $10(40.0)$ & $12(46.2)$ & $11(44.0)$ & $12(48.0)$ & $35(46.1)$ & $45(44.6)$ \\
\hline Minimally classic, n (\%) & $12(48.0)$ & $10(38.5)$ & $8(32.0)$ & $7(28.0)$ & $25(32.9)$ & 37 (36.6) \\
\hline Predominantly classic, $\mathrm{n}(\%)$ & $3(12.0)$ & $4(15.4)$ & $6(24.0)$ & $6(24.0)$ & $16(21.1)$ & $19(18.8)$ \\
\hline
\end{tabular}


Figure 2 Best-corrected visual acuity (BCVA) results. (A) Mean change from baseline; (B) mean absolute score from screening.
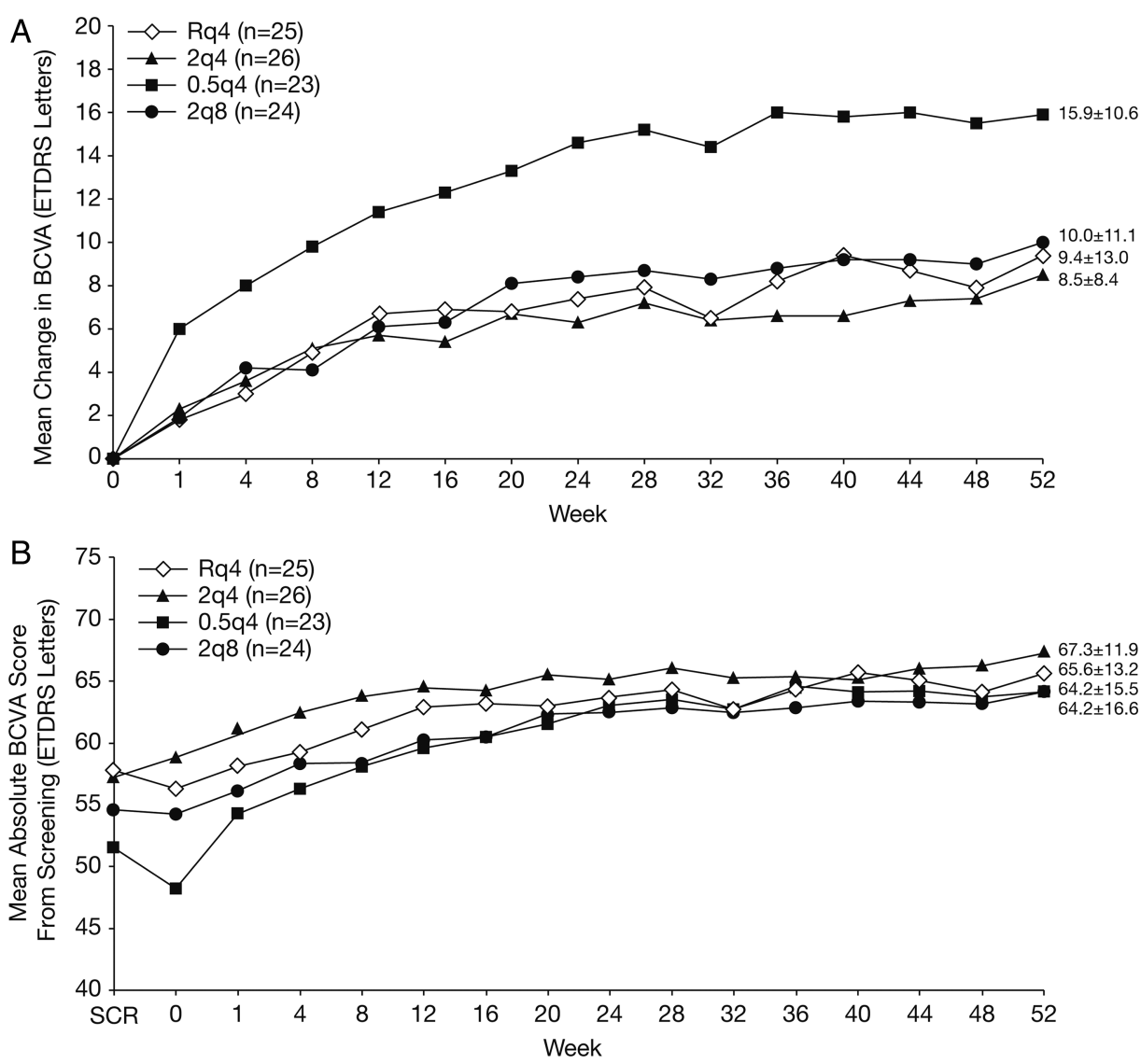

was not considered to be clinically meaningful given the small numbers of patients in each group. The ocular TEAEs reported in Japanese patients were similar to those in the overall VIEW 2 study population. Ocular injection-related TEAEs in the study eye were predominantly procedure-related events or associated with the underlying disease. The most frequent ocular injectionrelated adverse event was conjunctival haemorrhage (table 2).

No severe or serious ocular injection-related AEs were reported. These results are comparable to the overall VIEW 2 study population. No deaths were recorded.

The incidence of non-ocular TEAEs among Japanese patients was numerically higher in patients treated with IVT-AFL $(63.2 \%)$ than in ranibizumab-treated patients (48.0\%). However, most non-ocular TEAEs were reported in a single patient. Of the non-ocular TEAEs with higher incidences, no significant differences were detected among treatment groups.
Thus, the numerical differences in the rate of non-ocular TEAEs were not considered clinically relevant. One patient in the $0.5 \mathrm{q} 4$ group had a non-ocular TEAE, epistaxis, which was considered to be drug-related.

One patient in the $2 \mathrm{q} 8$ group experienced an Antiplatelet Trialists' Collaboration event of non-fatal myocardial infarction.

\section{DISCUSSION}

A subgroup analysis was conducted to demonstrate the safety and efficacy of IVT-AFL in the Japanese subpopulation of the VIEW 2 study. This subgroup analysis represents the largest study of anti-VEGF treatment for AMD conducted to date in a Japanese population. All IVT-AFL arms were considered to be non-inferior to $\mathrm{Rq} 4$ on the primary outcome, referring to a $10 \%$ non-inferior margin. These results are consistent with those observed in the overall population of the VIEW 2 study.
Figure 3 Central retinal thickness (CRT) results: mean change from baseline.

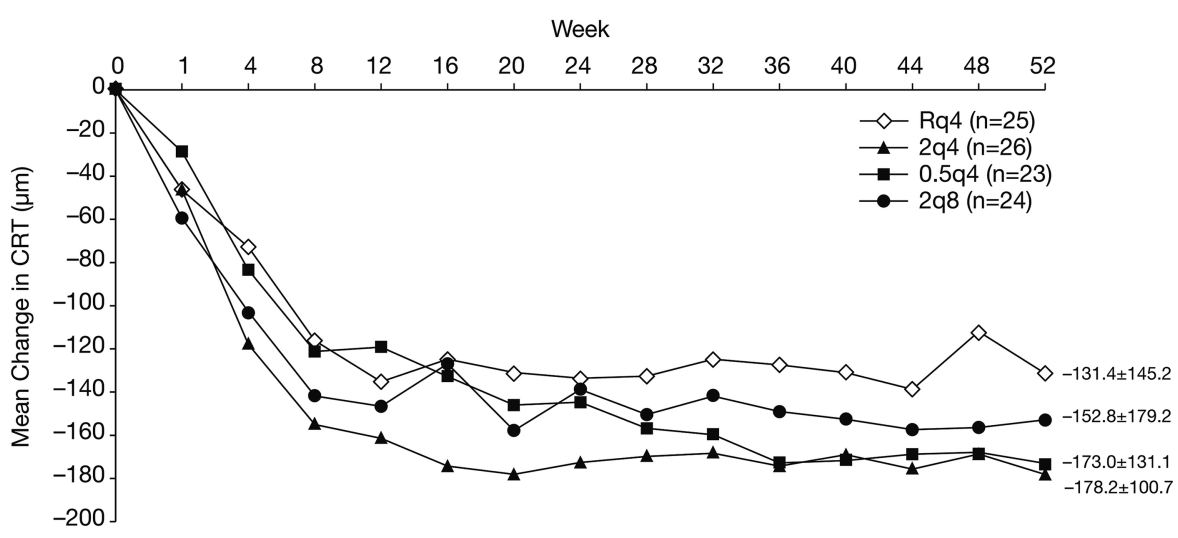


Table 2 Ocular injection-related TEAEs in the study eye ( $\geq 2 \%$ of patients)

\begin{tabular}{|c|c|c|c|c|c|c|}
\hline \multirow[b]{2}{*}{ Primary SOC-preferred term MedDRA V.13.1 } & \multirow{2}{*}{$\begin{array}{l}\text { Ranibizumab } \\
\text { Rq4 } \\
\text { n=25 }\end{array}$} & \multicolumn{4}{|c|}{ Intravitreal aflibercept } & \multirow{2}{*}{$\begin{array}{l}\text { Total } \\
\mathrm{n}=101\end{array}$} \\
\hline & & $\begin{array}{l}2 q 4 \\
n=26\end{array}$ & $\begin{array}{l}0.5 q 4 \\
n=25\end{array}$ & $\begin{array}{l}2 q 8 \\
n=25\end{array}$ & $\begin{array}{l}\text { IVT-AFL } \\
\text { combined n=76 }\end{array}$ & \\
\hline \multicolumn{7}{|l|}{ Eye disorders, $\mathrm{n}(\%)$} \\
\hline Abnormal sensation in eye & 0 & 0 & $1(4.0)$ & 0 & $1(1.3)$ & $1(1.0)$ \\
\hline Conjunctival haemorrhage & $6(24.0)$ & $3(11.5)$ & $6(24.0)$ & $7(28.0)$ & $16(21.0)$ & $22(21.8)$ \\
\hline Conjunctivitis & 0 & 0 & 0 & $1(4.0)$ & $1(1.3)$ & $1(1.0)$ \\
\hline Corneal erosion & $2(8.0)$ & 0 & $1(4.0)$ & 0 & $1(1.3)$ & $3(3.0)$ \\
\hline Corneal oedema & 0 & $1(3.8)$ & 0 & 0 & $1(1.3)$ & $1(1.0)$ \\
\hline Eye pain & $2(8.0)$ & $1(3.8)$ & $2(8.0)$ & 0 & $3(3.9)$ & $5(5.0)$ \\
\hline Eyelid oedema & $2(8.0)$ & 0 & 0 & 0 & 0 & $2(2.0)$ \\
\hline Foreign body sensation in eye & $1(4.0)$ & 0 & $1(4.0)$ & 0 & $1(1.3)$ & $2(2.0)$ \\
\hline Lacrimation increased & $1(4.0)$ & 0 & 0 & 0 & 0 & $1(1.0)$ \\
\hline Ocular hyperaemia & $2(8.0)$ & $2(7.7)$ & 0 & 0 & $2(2.6)$ & $4(4.0)$ \\
\hline Punctate keratitis & 0 & $1(3.8)$ & $1(4.0)$ & $1(4.0)$ & $3(3.9)$ & $3(3.0)$ \\
\hline Retinal pigment epithelial tear & 0 & 0 & 0 & $1(4.0)$ & $1(1.3)$ & $1(1.0)$ \\
\hline Vitreous floaters & $3(12.0)$ & $2(7.7)$ & 0 & $1(4.0)$ & $3(3.9)$ & $6(5.9)$ \\
\hline Vitreous opacities & 0 & 0 & $1(4.0)$ & 0 & $1(1.3)$ & $1(1.0)$ \\
\hline \multicolumn{7}{|c|}{ General disorders and administration site conditions, $\mathrm{n}(\%)$} \\
\hline Injection site pain & $1(4.0)$ & 0 & 0 & 0 & 0 & $1(1.0)$ \\
\hline \multicolumn{7}{|l|}{ Investigations, $\mathrm{n}(\%)$} \\
\hline Intraocular pressure increased & 0 & 0 & 0 & $1(4.0)$ & $1(1.3)$ & $1(1.0)$ \\
\hline \multicolumn{7}{|l|}{ Surgical and medical procedures, $\mathrm{n}(\%)$} \\
\hline Intraocular injection* & $1(4.0)$ & 0 & $1(4.0)$ & 0 & $1(1.3)$ & $2(2.0)$ \\
\hline
\end{tabular}

Visual and anatomical outcomes, as well as incidence of adverse events, were comparable between Japanese patients and the overall VIEW 2 population.

Mean ETDRS letter score at baseline in the $0.5 \mathrm{q} 4$ group (48.3) was the lowest among treatment groups. Results from this subpopulation analysis and from the complete VIEW 2 study population indicate that mean BCVA at baseline had an impact on mean change in BCVA from baseline, with higher baseline BCVA means associated with lesser VA gains, as reported in the Comparison of Age-related macular degeneration Treatment Trials (CATT) trial. ${ }^{18}$ Among Japanese patients, 14 patients in the $0.5 \mathrm{q} 4$ group had a baseline BCVA score $<50,1.6-2.8$ times more than other groups. Additionally, there were three specific patients, evaluated at two different centres, whose BCVA score decreased by more than 10 letters from screening to baseline, and then increased by an average of 29.3 letters from baseline to week 1, whereas the average BCVA score gain in the other three treatment groups at week 1 was 2.0.

The high BCVA improvement seen in the $0.5 \mathrm{q} 4$ group may be explained by the relatively small sample size and imbalances in baseline disease characteristics (ie, BCVA score and area of $\mathrm{CNV}$ ). Japanese patients in the groups unaffected by these imbalances showed a similar degree of mean BCVA changes compared to those of non-Japanese patients. Trends in BCVA scores throughout the first treatment year were similar among Japanese patients in the $2 \mathrm{q} 8$ group (which is the proposed dosing regimen in Japan) and the $2 \mathrm{q} 4$ group (despite a better $2 \mathrm{q} 4$ BCVA baseline) as compared with the complete VIEW 2 study population.

The mean areas of CNV at baseline in the $0.5 \mathrm{q} 4$ group $\left(5.46 \mathrm{~mm}^{2}\right)$ and $2 \mathrm{q} 4$ group $\left(5.07 \mathrm{~mm}^{2}\right)$ were lower compared to the other groups $\left(\mathrm{Rq} 4,8.06 \mathrm{~mm}^{2} ; 2 \mathrm{q} 8,6.86 \mathrm{~mm}^{2}\right)$. A subpopulation analysis conducted on the full study populations of VIEW 1 and VIEW 2 indicated that the area of CNV at baseline has an impact on mean change from baseline in BCVA, with a larger area of $\mathrm{CNV}$ at baseline associated with less VA gains (Ho A, et al IOVS 2012;53:ARVO E-Abstract 3678).

Few major differences in VA outcomes were observed for Japanese patients compared with the overall VIEW 2 study population. The area of CNV lesion was slightly smaller in the Japanese subgroup compared with the complete VIEW 2 study population (range: $5.1-8.1 \mathrm{~mm}^{2}$ vs $7.7-8.3 \mathrm{~mm}^{2}$, respectively). As described earlier, this is related to the higher incidence of classic $\mathrm{CNV}$ in Asian patients with AMD. Although sample numbers were small for this subanalysis, the distribution of BCVA gains and losses showed a similar trend to those of patients in the full VIEW 2 study. Moreover, mean change in BCVA was one to two lines of vision for the Japanese subpopulation and the overall population of the VIEW 2 study for the currently recommended therapeutic doses of ranibizumab and IVT-AFL (Japanese range: 8.5-15.9 ETDRS letters; overall VIEW 2 study population range: 7.6-9.7 letters). Differences observed between regions are likely to be a reflection of natural variability, which may be confounded by the smaller number of Japanese patients $(n=101)$ compared with patients outside Japan and the total study population (VIEW 1, N=1217 and VIEW 2, $\mathrm{N}=1240$ ). Based on PMDA guidelines, ${ }^{17}$ results for the Japanese subpopulation were found to be consistent with the whole study population.

PCV was not a cause for exclusion from the study. Formal diagnosis of PCV requires indocyanine green angiography, which was not stipulated as a mandatory test in the VIEW 2 
study. Therefore, Japanese patients' PCV status was classified according to diagnostic criteria based on baseline FA/fundus photography findings. Further analysis of the effects of anti-VEGF treatment in patients with PCV is required.

IVT-AFL is as well tolerated and effective in the Japanese wAMD population as in the full VIEW 2 study population. This subgroup analysis suggests that the results of the overall VIEW 2 study are representative of wAMD Japanese patients despite some unique disease presentations in Asian, including Japanese, eyes.

\section{Author affiliations}

${ }^{1}$ Department of Ophthalmology and Visual Science, Nagoya City University Graduate School of Medical Sciences, Nagoya, Japan

${ }^{2}$ Department of Ophthalmology, Nagoya University Graduate School of Medicine, Nagoya, Japan

${ }^{3}$ Department of Ophthalmology, Osaka University Graduate School of Medicine, Osaka, Japan

${ }^{4}$ Department of Ophthalmology, Nihon University School of Medicine, Tokyo, Japan ${ }^{5}$ Department of Ophthalmology, Tokyo Women's Medical University, Tokyo, Japan

${ }^{6}$ Department of Ophthalmology, Juntendo University Urayasu Hospital, Chiba, Japan

${ }^{7}$ Bayer Yakuhin, Ltd., Osaka, Japan

${ }^{8}$ Bayer HealthCare Pharmaceuticals, Berlin, Germany

${ }^{9}$ Department of Ophthalmology and Optometry, Medical University of Vienna, Vienna, Austria

${ }^{10}$ Vienna Reading Center (VRC), Medical University of Vienna, Vienna, Austria

${ }^{11}$ Oxford Eye Hospital, University of Oxford, Oxford, UK

Acknowledgements All Japanese investigators participated in the VIEW 2 study. Medical writing support was provided by Corey Eagan, MPH, and Alexandra Silveira, $\mathrm{PhD}$, of PAREXEL, which was funded by Bayer HealthCare Pharmaceuticals.

Collaborators VIEW 2 Investigators.

Contributors All authors were involved in the conception and design, acquisition of data, or analysis and interpretation of data in the VIEW 2 study. Additionally, all authors were involved in the drafting and revision of the article for intellectual content and the approval of the final version to be published.

Funding The VIEW 2 study was supported by Bayer HealthCare Pharmaceuticals, Berlin, Germany, and Regeneron Pharmaceuticals, Inc. Tarrytown, New York, USA

Competing interests $\mathrm{YO}, \mathrm{Tl}, \mathrm{MH}$ and $\mathrm{CS}$ report relationships with Bayer. HT reports relationships with Bayer, Novartis, Alcon, Santen, Senju, MSD, Pfizer and Nidek. FG reports relationships with Bayer and Santen. MY reports relationships with Bayer, Novartis, Alcon Japan, Pfizer, HOYA, Santen and Otsuka Pharmaceutical. US-E reports relationships with Bayer, Boehringer, Novartis, Allergan and Alcon. VC reports relationships with Bayer, Novartis, Allergan, Almeria Science and Quantel Medical. KN, OS and TK are employees of Bayer.

Ethics approval The study protocols were approved by institutional review boards or ethics committees for each clinical site.

Provenance and peer review Not commissioned; externally peer reviewed.

Open Access This is an Open Access article distributed in accordance with the Creative Commons Attribution Non Commercial (CC BY-NC 3.0) license, which permits others to distribute, remix, adapt, build upon this work non-commercially, and license their derivative works on different terms, provided the original work is properly cited and the use is non-commercial. See: http://creativecommons.org/ licenses/by-nc/3.0/

\section{REFERENCES}

1 Heier JS, Brown DM, Chong V, et al. Intravitreal aflibercept (VEGF trap-eye) in wet age-related macular degeneration. Ophthalmology 2012;119:2537-48.

2 Bird AC. The Bowman lecture. Towards an understanding of age-related macular disease. Eye (Lond) 2003;17:457-66.

3 Kawasaki R, Wang JJ, Ji GJ, et al. Prevalence and risk factors for age-related macular degeneration in an adult Japanese population: the Funagata study. Ophthalmology 2008;115:1376-81, 1381.

4 Oshima Y, Ishibashi T, Murata T, et al. Prevalence of age related maculopathy in a representative Japanese population: the Hisayama study. $\mathrm{Br}$ I Ophthalmol 2001;85:1153-7.

5 Maruko I, lida T, Saito M, et al. Clinical characteristics of exudative age-related macular degeneration in Japanese patients. Am J Ophthalmol 2007;144:15-22.

6 Mori K, Horie-Inoue K, Gehlbach PL, et al. Phenotype and genotype characteristics of age-related macular degeneration in a Japanese population. Ophthalmology 2010;117:928-38.

7 Uyama M, Takahashi $\mathrm{K}$, Ida N, et al. The second eye of Japanese patients with unilateral exudative age related macular degeneration. Br J Ophthalmol 2000;84:1018-23.

8 Kawasaki R, Wang JJ, Amirul FM, et al. Is bilateral age-related macular degeneration less common in Asians than Caucasians? Ophthalmic Epidemiol 2011;18:253-8.

9 Saito M, lida T, Kano M. Intravitreal ranibizumab for exudative age-related macular degeneration with good baseline visual acuity. Retina 2012;32:1250-9.

10 Matsumiya W, Honda S, Kusuhara S, et al. Effectiveness of intravitreal ranibizumab in exudative age-related macular degeneration (AMD): comparison between typical neovascular AMD and polypoidal choroidal vasculopathy over a 1 year follow-up. BMC Ophthalmol 2013;13:10.

11 Lim LS, Mitchell P, Seddon JM, et al. Age-related macular degeneration. Lancet 2012;379:1728-38.

12 Hayashi H, Yamashiro K, Gotoh N, et al. CFH and ARMS2 variations in age-related macular degeneration, polypoidal choroidal vasculopathy, and retinal angiomatous proliferation. Invest Ophthalmol Vis Sci 2010;51:5914-19.

13 Gotoh N, Nakanishi H, Hayashi H, et al. ARMS2 (LOC387715) variants in Japanese patients with exudative age-related macular degeneration and polypoidal choroidal vasculopathy. Am J Ophthalmol 2009;147:1037-41, 1041.

14 Suzuki M, Gomi F, Sawa M, et al. Bevacizumab treatment for choroidal neovascularization due to age-related macular degeneration in Japanese patients. Jpn J Ophthalmol 2010;54:124-8.

15 Tano Y, Ohji M. EXTEND-I: safety and efficacy of ranibizumab in Japanese patients with subfoveal choroidal neovascularization secondary to age-related macular degeneration. Acta Ophthalmol 2010;88:309-16.

16 Tano Y, Ohji M. Long-term efficacy and safety of ranibizumab administered pro re nata in Japanese patients with neovascular age-related macular degeneration in the EXTEND-I study. Acta Ophthalmol 2011;89:208-17.

17 Basic principles on Global Clincal Trials. http://www pmda go jp/kijunsakusei/file/ guideline/new_drug/GlobalClinicalTrials_en pdf. http://www.pmda.go.jp/ kijunsakusei/file/guideline/new_drug/GlobalClinicalTrials_en.pdf

18 Ying GS, Huang J, Maguire MG, et al. Baseline predictors for one-year visual outcomes with ranibizumab or bevacizumab for neovascular age-related macular degeneration. Ophthalmology 2013;120:122-9. 